\title{
Nonpalpabl testislerin orșiopeksisi sırasında prosesus vaginalis diseke edilmeli ve yüksek ligasyon yapılmalıdır
}

\author{
During orchiopexy of the nonpalpable testis, the processus vaginalis should \\ be dissected and high ligation performed
}

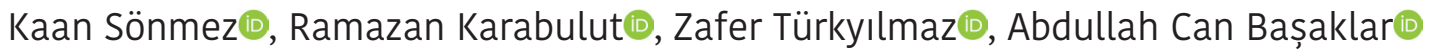

\section{öz}

AMAC̦: İnmemiș testisli hastalarda patent prosesus vaginalis (PPV) ve fitık birlikteliği ile ilgili veriler tartısmalıdır. Bazı pediatrik cerrah ve özellikle ürologlar PV'ye inmemiş testis ameliyatı sırasında dokunmazken, çoğunlukla fittk oluşumunu önlemek ve etkin bir orşiopeksi sonucu elde etmek için PV'yi disseke ederek yüksek ligasyon yaparlar. Bu çalışma, özellikle palpe edilemeyen inmemiş testisli olguların tedavisi sırasında PV disseksiyonu ve yüksek ligasyonun önemini vurgulamak için yapılmıştır.

GEREÇLER ve YÖNTEMLER: Çalışmaya alınan 64 nonpalpabl testis (NPT) olgusunun klinik bulguları ve cerrahi prosedürleri geriye dönük olarak incelendi.

BULGULAR: Ortalama hasta yaşı 2,6 $(1,0-12,5)$ yıl olarak bulundu. Sağ ve sol NPT sırasiyla 45 ve 19 hastada tespit edildi. Abdomino-skrotal ultrasonografide 11 hastada testis görüntülenemezken, dokuz hastada atrofik olarak saptandı. Dokuz hastada kasık şişliği bir ebeveyn tarafından vurgulanırken, 25 hastada inguinoskrotal muayene sırasında ipek belirtisi işareti veya PPV saptandı. Tüm hastalarda inmemiş testis ameliyatı inguinal yaklaşımla gerçekleştirildi. Operasyon sırasında ingunial kanal açıldı ve vakaların $45^{\prime}$ inde iç ring nomalden geniş çapta $(>2,5 \mathrm{~cm})$ ve inguinal tabanın bu genişliğe bağlı zayıf olduğu görüldü. Ayrıca testis iç ringden inguinal kanala doğru çekildiğinde testisin $\mathrm{PV}$ içinde izlenimi verdiği ve PV'nin çok ince ve frajil olduğu görüldü. Tüm hastalara PV disseksiyonu ve yüksek ligasyon uygulandı. Hastalarımızın ikisinde kademeli orşiopeksi gerekirken, 18 'inde Prentiss manevrası ile, diğer vakalarda da normal prosedür ile skrotumda subdartos poş hazırlanarak orşiopeksi tamamlanmıştır. Ameliyat sonrası skrotal ödem altı, yara enfeksiyonu üç hastada tespit edildi. İzlemde iki vakada testiküler atrofi, dört vakada da nüks inmemiş testis tespit edildi. Hiçbir hastamızda takip sırasında inguinal fitık gelişmezken, tüm operasyonlar günübirlik olarak gerçekleştirildi.

SONUÇ: PV'nin disseksiyon ve yüksek ligasyonu başarılı orşiopeksi ve kasık fitığının önlenmesi için palpe edilemeyen ve inmemiş testisli hastalarda etkili bir yöntemdir.

Anahtar Kelimeler: prosesus vaginalis, inmemiş testis, yüksek ligasyon, fitık, orşiopeksi

Gazi Üniversitesi Tıp Fakültesi, Çocuk Cerrahisi Anabilim Dalı, Ankara

Yazışma Adresi/ Correspondence:

Prof. Dr. Ramazan Karabulut

Besevler 06550 Ankara, Türkiye

Tel. $\quad$ +905426818481

E-mail: karabulutr@yahoo.com

Geliş/ Received: $\quad 07.03 .2018$

Kabul/ Accepted: 22.03 .2018

\section{ABSTRACT}

OBJECTIVE: Data on the prevalence of patent processus vaginalis (PPV) and hernia in patients with cryptorchidism are controversial. While some pediatric surgeons do not dissect the PV, most prefer to do so to prevent hernia formation, and to achieve an effective orchiopexy outcome. This study was performed to evaluate the importance of dissection and high ligation of the processus vaginalis (PV) during treatment of undescended testis (UT).

MATERIALS and METHODS: The clinical findings and surgical procedures of 64 patients with UT were retrospectively investigated.

RESULTS: The mean patient age was 2.6 (range, 1.0-12.5) years. Nonpalpable testes (NPT) were located on the right and left side in 45 and 19 patients, respectively. Ultrasonography revealed no testis in 11 patients, and an atrophic testis in 9 patients. Nine patients had a parent with an inguinal hernia, and the silk sign or a patent PV was detected during inguinoscrotal examination in 25 patients. UT repairs were performed by an inguinal approach in all patients. The inguinal canal was opened in all patients; 45 patients had a wider-than-normal internal ring $(>2.5 \mathrm{~cm})$, and the posterior wall of the inguinal canal was consequently weakened. Two-stage orchiopexy was performed in 2 patients, and 18 underwent the Prentiss maneuver. In the remaining patients, the dissection was easily performed and the testes were reduced without any difficulty. Scrotal edema and wound infection occurred in 6 and 3 patients, respectively. Two patients presented with an atrophic testis, and four had recurrent UT. Inguinal hernia was not observed in any of the patients during the study period, and all procedures were performed on an outpatient basis.

CONCLUSION: High ligation of the PV is an effective method for successful orchiopexy, and prevention of inguinal hernia in patients with NPT and UT.

Keywords: processus vaginalis, undescended testis, high ligation, hernia, orchiopexy

\section{Gíriș}

Bir yaşın üzerindeki hastalarda inmemiş testis insidansı $\% 2,2$ 'dir. Bu hastaların yaklaşık \%20'sinde palpe edilemeyen testis (NPT) vardır. NPT'li hastaların da yaklaşık yarısında testis karın boşluğunda bulunur; kalanında ise testis ya genellikle atrofiktir ya da antenatal torsiyon veya intra-uterin testis agenezisine sekonder palpe edilemez 
konumdadır. ${ }^{[1,2]}$ İnmemiş testisli hastalarda patent prosesus vaginalis (PPV) ve fitık birlikteliği ile ilgili veriler tartışmalıdır. Bazı pediatrik cerrah ve özellikle ürologlar PV'ye ameliyat sırasında dokunmazken, çoğunluk ise fitık oluşumunu önlemek ve etkin bir orşiopeksi sonucu elde etmek için PV'yi disseke ederler. ${ }^{[3-5]}$ Genel olarak iç inguinal halka açıklığının $1 \mathrm{~cm}$ 'den küçük olması laparoskopik fıtık onarımında cerrahi için bir endikasyon değildir. Eğer bu açıklık $2,5 \mathrm{~cm}$ üzeri ise genelde kese disseksiyonu ve süturasyon önerilmiştir. ${ }^{[6]} \mathrm{Bu}$ çalışmanın amacı, iç inguinal halka düzeyinde veya karın içi konumda olan inmemiş testislerin onarımı sırasında PV'nin spermatik kord ve testis damarlarından disseksiyonu ve yüksek ligasyonunun önemini vurgulamaktır.

\section{YÖNTEM}

Kliniğimizde 1998-2017 yılları arasında 1420 inmemiş testis vakası opere edilirken bunların sadece 64'ü NPT idi. Bu çalışmada orşiopeksi yapılan 64 karın içi yerleşimli NPT vakasının yaşı, tarafı, klinik bulguları ve cerrahi işlemleri geriye dönük olarak incelendi.

\section{BULGULAR}

Ortalama hasta yaşı 2,6 $(1,0-12,5)$ yıl olarak bulundu. Sağ ve sol tarafta NPT sırasıyla 45 ve 19 hastada tespit edildi. Operasyon öncesi yapilan fizik muayenede bu çocukların \%70 ( $\mathrm{n}=45)^{\prime}$ 'inde iç ring hizasında el altından kaçan ve testis olduğu düşünülen lezyon hissedilirken, geri kalan vakalarda testis palpe edilemedi. Skrotal ve abdominal ultrasonografi tüm hastalara yapıldı. Ultrasonografik olarak sadece 11 vakada testis görüntülenemezken, karşı testise göre ufak olarak inmemiş testis dokuz vakada tespit edildi. Bu hastaların dokuzunda inguinal fitığa benzer şikayet ebeveynler tarafından görülürken, silk sign (ipek belirtisi) veya PPV inguino-skrotal muayenede 25 hastada tespit edildi. Hiç bir hastamızda bulant1, kusma ya da skrotum ve inguinal bölge eritemi gibi boğulmuş fitık belirti ve bulgusu yok idi. Hastaların inmemiş testis onarımı cilt katlantılarına paralel olacak şekilde inguinal kesi ile yapıldı. Tüm olgularda ingunial kanal eksternal oblik kas kesilerek açıldı ve vakaların 46'sında iç ring normalden geniş çapta $(>2,5$ $\mathrm{cm})$ olduğu görüldü. Ayrıca, testis karından doğurtularak iç halkadan inguinal kanala doğru çekildiğinde; testisin PV içinde izlenimi verdiği ve bu olguların PV'sinin fıtık olgularınınkine kıyasla çok ince ve frajil olduğu görüldü. Bu genişlik nedeniyle intraperitoneal sıvının rahatça PPV içine girdiği ve fitık kesesini taklit eder biçimde şiş olduğu görüldü. Bu inmemiş testislerin orşiopeksisi sırasında genişlemiş PV'nin vas deferens ve pleksus pampiniformisten disseksiyonu yanında PV'nin bu yapılardan tamamen ayrıldıktan sonra pre-peritoneal yağ dokusu hizasında (iç inguinal halka seviyesi) çepeçevre dönülüp yüksek ligasyonu $4 / 0$ poliglaktin ile yapıldı. Bu işlem yapılırken normalden genişlemiş ve çok ince olan PV \%29,6 (19 vaka) oranında açılmasına rağmen 64 vakada da yüksek ligasyon tamamıyla yapılabildi. Artmış iç inguinal halka çapı, testisin karın içinden PV içine doğar nitelikte olması ve çok gergin inmemiş testis olması yüzünden, bu vakaların orşiopeksisi sırasında PV açılsa bile daha kolay onarım için PV disseksiyonuna daha dar alanda çalışılarak iç ring hizası ile testisin ortası mesafeden başlandı. Hasta testislerinin rahat inmesi için \%3,1 oranında (iki hasta) kademeli ve \%28,1 oranında (18 hasta) Prentiss manevrası ile orşiopeksi yapıld. Diğer 44 hasta da ise skrotumda subdartos poş hazırlanarak orşiopeksi işlemi tamamlandı. Tüm ameliyatlar günübirlik cerrahi ile gerçekleştirildi. Skrotal ödem \%9,3 (altı hasta) oranında ve yara enfeksiyonu \%4,6 (üç hasta) oranında hastalarda ilk haftada görüldü. Ortalama 2,9 yıl (9 ay - 10 yll) izlemde; \%3,1 (iki vaka) testiküler atrofi ve \%6,2 (dört vaka) nüks inmemiş testis tespit edildi. Bu nüks olan bir vakaya Prentiss onarımı, diğer üç vakaya ise tekrar klasik orşiopeksi ameliyatı yapılması gerekti. Takipte hiçbir hastamızda inguinal fıtık gelişmedi.

\section{TARTIȘMA}

Doğumdan sonra testis ve abdominal kavite arası PPV kapanır ve peritoneal kavite ile ilişki kesilerek sadece testisi saracak konuma gelir. Eğer bu kapanma işlemi yetersiz olursa fitık ya da hidrosel gibi çeşitli klinik durumlar ortaya çıkar. ${ }^{[]}$Çocuklarda fitık oranı $\% 0$ ile $\% 4,4$ arasında değişirken, PPV'nin açık kaldığı erken doğmuş bebeklerde bu oran \%16-25 gibi yüksek oranlara çıkmaktadır. ${ }^{\left[{ }^{[]}\right.}$ Çoğu gerçek inmemiş testis vakaları (\%90) hatta retraktil testisler bile PPV ile birliktedir. Elder çalışmasında NPT olgularına laparoskopi yapmış ve testisin olduğu görülen 47 vakanın 43'ünde PPV (\%91) tespit etmişken, PV'si kapalı olan 77 vakanın 75'inde (\%97) testisin olmadığını göstermiştir. ${ }^{[9]}$ Barthold PPV görülen fitık, hidrosel ve inmemiş testis vakalarında epididimal anomalileri incelemiş ve inmiş testislerde $\% 34$ ve inmemiş testislerde $\% 72$ epididimal anomali göstermiştir. Sonuçta androjenik uyarının PV'nin kapanması için gerekli olduğunu ve inmemiş testislerde PPV oranının artığını söylemiştir. ${ }^{[10]}$ Radmayr ve ark. ise inmemiş testislerde $\% 26$ ile belirgin olarak artmış inguinal fitık bildirmişlerdir. ${ }^{[1]]}$ Klasik olarak inmemiş testis operasyonu sırasında fitık kesesinin ya da PV'nin iç ring hizasında yeterli disseksiyonu sonrası yüksek ligasyonu önerilmektedir. Jain ve ark., yaşları 6 ay ile 10 yıl arası olan toplam 450 orşiopeksi vakasını incelemiş ve bunların hiçbirinde klinik olarak belirgin fitık tespit etmemiştir. 
Onlarca kese ya da PV'yi açmışlar ve iç ring hizasında kord ve elamanlarından ayırarak hiçbir hastada yüksek ligasyon yapmadan orşiopeksiyi tamamlamışlardır. Bu hastaların takiplerinde fitık gelişmemiştir. Fakat bu serinin tamamı palpabl inmemiş testis vakalarından oluşmaktadır. ${ }^{[4]}$ Hatta Mohta ve ark., çocuk inguinal herni onarımlarında bile $\mathrm{fl}_{1}$ tık kesesinin yüksek ligate edilmemesini önermişlerdir. ${ }^{[5]}$ Schier laparoskopik fitık onarımında fitık kesesinin kesilmesi ile bağlanmasının birbirinden farklı olmadığını ve açık iç inguinal halkanın fitık anlamı taşımadığını söylemiştir.

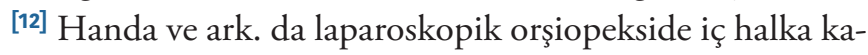
patılmasının gereksiz olduğunu ifade etmiştir. ${ }^{[13]}$ Blacburn ve ark., Fowler-Stephens orşiopeksi yaptıkları vakalarda sadece indirekt fitık kesesini ayırarak yüksek ligasyon yapmamışlardır. Yaklaşık 2,7 yıl takiplerde, direkt ya da indirekt herni görmemişlerdir. ${ }^{[14]}$ Bunların tersine, Varela-Cives ise inmemiş testislerde herniografi yaparak PPV'yi araştırmış; 376 inmemiş testis vakasında 95 PPV $(\% 25,3)$ saptarken, normal inmiş testislerde 244 vakada 31 (\%12,7) PPV bulmuşlardır $(\mathrm{p}=0,0001)$. Ayrıca, yaşı küçük olanlarda daha fazla PPV oranı olduğunu söyleyerek, NPT'lerde \%41,23 oranında PPV göstermişlerdir. ${ }^{[15]}$ İki prospektif çalışmada da inmemiş testisli çocukların ameliyatı sırasında (klinik fıtık ve hidrosel olan vakalar dışarda bırakıldığında) PPV sırasıly $\% 71$ ve $\% 77$ tespit edilmiştir. ${ }^{[16,17]}$ İnmemiş testisli hastaların PPV varlığı, hasta yaşı ve testis pozisyonu ile alakalıdır. Eğer hasta 2 yaş altı ise PPV görülme sıklığı $\% 68,7$ iken bu oran dramatik olarak düşecek şekilde 2-6 yaş arası \% 27,2 ve 6-12 yaş arası ise \%11,2 bulunmuştur. İç inguinal halka ya da karın içi yerleşimli inmemiş testislerde daha aşağı yerleşimli inmemiş testislere göre belirgin artmış PPV saptanmıştır. ${ }^{[15]}$ Ceccanti ve ark.'nın 123 hasta ve 147 orşiopeksilik serisinde olgular PV'nin disseke edilip yüksek ligasyon yapıldığı ve sadece disseke edilip yüksek ligasyon yapılmadığı şeklinde iki gruba ayrılarak takip edilmiştir. Ortalama 39 aylık takipte her iki grupta da fitık görülmediği bildirilmiştir $(p=0,16)$. Yüksek ligasyon yapılan grupta bir, yapılmayan grupta ise iki inmemiş testis nüksü görülmüştür $(\mathrm{p}=0,42)$. Fakat bu iki grup da NPT içermeyen, inguinal kanal ve preskrotal yerleşimli inmemiş testis vakalarından oluşmaktadır. ${ }^{[18]}$ Benzer şekilde, skrotal orşiopeksi yapılan preskrotal yerleşimli inmemiş testisli 137 hasta ve 227 inmemiş testis vakasında PV ligasyonu yapılmamış ve bu hastalarda da fitık gelişmemiştir. $\mathrm{Bu}$ araştırmacılar da inmemiş testis ameliyatlarında yüksek ligasyon önermemiştir. ${ }^{[19]}$ Ameliyat sonrası fitık görülmemesinin sebebi, peritonunun mezodermal hücrelerinde in situ metamorfoza bağlı spontan iyileşmesine bağlanmıştır. [5] Üstteki bilgiler 1şı̆̆gnda, inmemiş testislerin indirilmesinde PPV bağlayan ya da bağlamayan makaleler kendi görüşlerini destekleseler de, biz tüm olgularımızda rahat bir orşiopeksi ve yüksek başarı için PPV disseksiyonunu yaptık. Burada sadece NPT vakalarının seçilme nedeni ise, bu vakalardaki PPV oranın daha yüksek görülmesi yanı sıra, testisin diğer inmemiş testis vakalarına göre daha gergin olduğu için PPV disseksiyon ve yüksek ligasyon işleminin gerekliliğini vurgulamaktır. Eğer belirgin fitığı var olan çocukta tanı anında inmemiş testis varsa, orşiopeksi fitık onarımı ile birlikte yapılabilir. Böyle olmayan vakalarda ise fıtık onarımı orşiopeksi zamanında yapılabilir. Riquelma ve ark.'nın laparoskopik orşiopeksi serisinde 31 hastanın 23 'ünde $(\% 69,9)$ inguinal fitık tespit edilmiştir (yorumda bunların klinik olarak belirgin fitık olmadığı sadece açık iç inguinal halka olduğu vurgulanmış) ve bunların 16'sı palpapl iken yedisi NPT imiş. Laparoskopi ile sadece PPV çıkarılmış, fıtık için onarım yapılmamış ve hiçbir hastada takipte fitık gelişmediği söylenmiştir. ${ }^{[7]}$ Bizim çalışmamızda, operasyon öncesi dokuz vakada aile tarafından ve 25 vakada ise fizik muayene sırasında silk sign bulgusu tespit edildi. Operasyon sırasında ise NPT olgularının hepsinde geniş bir PPV olduğu görüldü. PV'nin yüksek ligasyonu ve testisin orşiopeksisi sonrasında hiçbir vakamızda fitık tespit edilmemesi, yaptığımız işlemin uygunluğunun göstergesidir. Biz bu vakalarda açık orşiopeksiyi tercih ettik, çünkü yeterli PPV ya da kese disseksiyonu ve yüksek ligasyonun inmemiş testis tedavisi için başlıca faktör olduğuna inanmaktayız. Bu yaklaşım, yüksek ligasyon için hazırlanan PPV'in kontrollü açılarak karın içine bakılmasına ve testis araştırılmasına da izin vermektedir. PPV disseksiyonuna iç ring ve testis arası bölgeden yapılarak başlanmalıdır. Bu yaklaşım sayesinde, daha küçük çapta PV'nin disseksiyonu yapılmakta ve PV açılsa bile iç ring hizasında yapılan onarımlara göre daha kolay toparlanarak onarılması sağlanmaktadır. Ayrıca, PV'nin klasik olarak bu şekilde yüksek ligate edilmesi; karın içinden indirilen inmemiş testis vakalarının indirilebilecek en mükemmel noktaya, daha az gerginlikte indirilmesi ya da tespitini sağlamakta, Prentiss onarımı için ortam oluşturmakta ve ileride geniş iç halka veya taban bozukluğuna bağlı inguinal fitıklar oluşmasını engellemektedir. Fakat, literatürde bu tür bir çalışma olmayıp, özellikle NPT vakalarında PV'nin disseke edilip yüksek ligate edildiği ve edilmediği şeklinde iki grup oluşturarak prospektif bir çalışma yapılmasının bu konuyu daha iyi aydınlatacağı kanaatindeyiz.

\section{SONUÇ}

Laparaskopik ya da açık orşiopeksi sırasında özellikle NPT ve diğer inmemiş testis vakalarında ileride oluşabilecek fitığı engellemek ve testisin daha da aşağıya indirilmesi için prosesus vaginalis yüksek ligate edilmelidir. Böylece testise zarar verecek ikincil ameliyatlara da gerek kalmayacaktır. 


\section{Hakem Değerlendirmesi}

Dış bağımsız

Çıkar Çatışması

Yazarlar çıkar ilişkisi olmadığını beyan etmişlerdir.

Finansal Destek

Herhangi bir mali destek alınmamıştır.

Peer-review

Externally peer-reviewed.

\section{Conflict of Interest}

No conflict of interest was declared by the authors.

Financial Disclosure

No financial disclosure was received.

\section{KAYNAKLAR}

1. Berkowitz GS, Lapinski RH, Dolgin SE, Gazella CA, Holzman IR. Prevalence and natural history of cryptorchidism. Pediatrics 1993;92:44-9.

2. Levitt SB, Kogan SJ, Engel RM, Weiss RM, Martin DC, Ehrlich RM. The impalpable testis: a rational approach to management. J Urol 1978;120:515-20.

3. Leung AK, Robson WL. Current status of cryptorchidism. Adv Pediatr 2004;51:351-77.

4. Jain VK, Singh S, Garge S, Joshi M, Sanghvi J. Orchidopexy san ligation technique of orchidopexy. Afr J Paediatr Surg 2011;8:1124. [CrossRef]

5. Mohta A, Jain N, Irniraya KP, Saluja SS, Sharma S, Gupta A. Nonligation of hernial sac during herniotomy: a prospective study. Pediatr Surg Int 2003;19:451-2. [CrossRef]

6. Shehata SM, ElBatarny AM, Attia MA, El Attar AA, Shalaby AM. Laparoscopic Interrupted Muscular Arch Repair in Recurrent Unilateral Inguinal Hernia Among Children. J Laparoendosc Adv Surg Tech A 2015;25:675-80. [CrossRef]

7. Riquelme M, Aranda A, Rodriguez C, Cortinas J, Carmona G, Riquelme-Q M. Incidence and management of the inguinal hernia during laparoscopic orchiopexy in palpable cryptoorchidism: preliminary report. Pediatr Surg Int 2007;23:301-4. [CrossRef]

8. Glick PL, Boulanger SC. Inguinal hernias and hydroceles. In: Coran AG, Adzick NS, Krummel TM, Laberge J-M, Shamberger R, Caldamone AA, editors. Pediatric Surgery, 2-Volume Set, 7th ed. PA: Elsevier Saunders; 2012. pp. 985-1001.
9. Elder JS. Laparoscopy for impalpable testes: significance of the patent processus vaginalis. J Urol 1994;152(2 Pt 2):776-8.

10. Barthold JS, Redman JF. Association of epididymal anomalies with patent processus vaginalis in hernia, hydrocele and cryptorchidism. J Urol 1996;156:2054-6.

11. Radmayr C, Corvin S, Studen M, Bartsch G, Janetschek G. Cryptorchidism, open processus vaginalis, and associated hernia: laparoscopic approach to the internal inguinal ring. Eur Urol 1999;36:631-4. [CrossRef]

12. Schier F. Laparoscopic inguinal hernia repair -aprospective personal series of 542 children. J Pediatr Surg 2006;41:1081-4. [CrossRef]

13. Handa R, Kale R, Harjai MM. Laparoscopic orchiopexy: is closure of the internal ring necessary? J Postgrad Med 2005;51:266-7.

14. Blackburn SC, Adams SD, Mahomed AA. Risk of hernia occurrence where division of an indirect inguinal sac without ligation is undertaken. J Laparoendosc Adv Surg Tech A 2012;22:713-4. [CrossRef]

15. Varela-Cives R, Bautista-Casasnovas A, Taboada-Santomil P, Estevez-Martinez E, Mendez-Gallart R, Pombo-Arias M, TojoSierra R. Relevance of herniography for accurate diagnosis of patent processus vaginalis in cryptorchidism. Int Braz J Urol 2008;34:57-62.

16. Adamsen S, Aronson S, Börjesson B. Prospective evaluation of human chorionic gonadotropin in the treatment of cryptorchidism. Acta Chir Scand 1989;155:509-14.

17. Hazebroek FW, de Muinck Keizer-Schrama SM, van Maarschalkerweerd M, Visser HK, Molenaar JC. Why luteinizinghormone-releasing-hormone nasal spray will not replace orchiopexy in the treatment of boys with undescended testes. J Pediatr Surg 1987;22:1177-82.

18. Ceccanti S, Zani A, Mele E, Cozzi DA. Orchidopexy without ligation of the processus vaginalis is not associated with an increased risk of inguinal hernia. Hernia 2014;18:339-42. [CrossRef]

19. Hyuga T, Kawai S, Nakamura S, Kubo T, Nakai H. Long-Term Outcome of Low Scrotal Approach Orchiopexy without Ligation of the Processus Vaginalis. J Urol 2016;196:542-7. [CrossRef] 